\title{
PROGRAMAÇÃO, CONEXÃO E AVALIAÇÃO DE PSICRÔMETRO ASPIRADO DE TERMOPAR DE BAIXO CUSTO EM MICROLOGGER PARA ESTUDOS AGROMETEOROLÓGICOS
}

\author{
ANTONIO RIBEIRO DA CUNHA \\ Universidade Estadual Paulista, Faculdade de Ciências Agronômicas, Departamento de Solos e Recursos \\ Ambientais, Botucatu, SP, Brasil \\ arcunha@fca.unesp.br
}

Recebido Janeiro de 2012 - Aceito Outubro de 2012

\begin{abstract}
RESUMO
Como o método psicrométrico é considerado padrão para a medida da umidade relativa do ar, muitas pesquisas têm utilizado psicrômetros aspirados de termopares conectados em microloggers, mas, no entanto, não detalham a forma de como é feita a aspiração da corrente de ar. Contudo, uma das maiores dificuldades dos psicrômetros aspirados de termopar têm sido a programação e a conexão em micrologger pelo usuário, pois exige especificidade na forma de programação, conexão e habilidade na obtenção de medidas acuradas. Assim, este trabalho teve o objetivo de fornecer a programação e a conexão do psicrômetro aspirado de termopar tipo T, conectado nos microloggers CR10X e CR23X da Campbell Scientific, avaliando-se a qualidade das medidas obtidas de temperatura e umidade relativa do ar em relação a um sensor Vaisala HMP50. As medidas não contínuas foram feitas no período de 04/09/2006 a 11/07/2007 em Jaboticabal, SP. As medidas de temperatura do ar foram semelhantes entre os sensores Vaisala e psicrômetro aspirado de termopar, mas nas medidas de umidade relativa do ar, houve diferenças significativas, sendo que as medidas obtidas pelo psicrômetro aspirado de termopar conectado ao CR10X foram as mais precisas. Utilizando a programação e a conexão de um micro-ventilador 12 VDC da forma sugerida para aspirar os bulbos seco e úmido do psicrômetro aspirado de termopar, nos microloggers modelos CR10X e CR23X, é possível obter medidas de temperatura do ar com boa precisão e exatidão, mas, no entanto, medidas de umidade relativa do ar com boa precisão e exatidão nem sempre é atingida, devido às dificuldades inerentes ao processo físico que ocorre no bulbo úmido, a habilidade e manutenção no uso deste equipamento, e a proteção do reservatório contra os efeitos radiativos.
\end{abstract}

Palavras-Chave: automatização, sistema de aquisição de dados, termopar, temperatura do ar e umidade relativa.

\footnotetext{
ABSTRACT: PROGRAMMING, CONNECTIONANDAVALIATIONOFALOWCOSTASPIRATED THERMOCOUPLE PSYCHROMETER IN MICROLOGGER FOR AGROMETEOROLOGICAL STUDIES:

As the psychrometric method is considered standard for the measurement of relative humidity, many studies have used aspirated thermocouple psychrometers connected to microloggers but, however, they do not detail how the aspiration of the air stream is done. However, one of the major difficulties of aspirated thermocouple psychrometers is to program and to connect it in micrologger, because specific programming and connection are requires, and still some skills in getting accurate measurements. This work aimed to provide the programming and the connection of the aspirated thermocouple psychrometer type T for the CR10X microloggers and CR23X of Campbell Scientific, evaluating the quality of measurements of temperature and air relative humidity in relation the a sensor Vaisala HMP50. The non-continuous measurements were made in the period 2006/09/04 to 2007/07/11 at Jaboticabal, SP. The air temperature measurements were similar between the Vaisala sensors and aspirated thermocouple psychrometer, but the relative humidity measurements were significantly
} 
different. The measurements obtained by the aspirated thermocouple psychrometer connected to CR10X micrologger were the most accurate. Using the programming and connection of a micro-fan to suck in the dry and moist bulbs of aspirated thermocouple psychrometer in microloggers models CR10X and CR23X, it is possible to obtain measurements of air temperature with good precision and accuracy, and measurements of air relative humidity with good precision, but accuracy is not always attainable due to the difficulties inherent to the physical processes that occur in the wet bulb, the skill in the use and maintenance of this equipment and the reservoir protection against radiative effects.

Keywords: automatization, micrologger, thermocouple, air temperature and relative humidity.

\section{INTRODUÇÃ̃O}

O psicrômetro é o instrumento mais utilizado para a determinação do conteúdo do vapor d'água da atmosfera (Fritschen e Gay, 1979; White e Ross, 1991), pois permite bom nível de precisão e exatidão quando é confeccionado com termopares de cobre-constantan (Cunha et al., 2001; Marin et al., 2001), sendo que a medida da umidade relativa do ar é obtida a partir da diferença entre as temperaturas de bulbos seco e úmido, sendo considerado método padrão para a medida da umidade relativa (WMO, 2008).

O termômetro de bulbo seco mede a temperatura do ar, e no de bulbo úmido ocorre o fenômeno de evaporação potencial, reduzindo a temperatura neste bulbo em função da mecha de algodão estar saturada com água. Muitos parâmetros estão envolvidos para garantir que a temperatura atingida seja realmente a de saturação, garantindo a exatidão das medidas, tais como a pureza da água, aspiração da corrente do ar, especificação e estado da mecha, trocas radiativas, efeitos da pressão, e outros (ASHRAE STANDARD 41.6, 1994).

Os psicrômetros de bulbos seco e úmido apresentam boa estabilidade nas medidas desde que a amostra de ar seja adequadamente umidificada pela água evaporada da mecha de algodão. Permitem medidas de altas temperaturas e de ampla faixa de umidade, e toleram a condensação, mas, no entanto, exigem habilidade no seu uso e manutenção, pois impurezas do ar ou da água contaminam a mecha de algodão exigindo limpeza e/ou troca periódicas.

O termopar é um sensor de temperatura muito simples, robusto, barato e de fácil utilização, como exemplo, o termopar tipo $\mathrm{T}$, liga de cobre mais liga de constantan ( $55 \%$ de cobre e $45 \%$ de níquel). Quando essas ligas são unidas em uma de suas extremidades, geram uma tensão elétrica que pode ser medida na outra extremidade desde que haja diferença de temperatura entre elas, pois a diferença de potencial é proporcional à diferença de temperatura entre suas junções, princípio denominado de efeito Seebeck. O termopar quando usado na confecção de psicrômetro é muito útil em estudos agrometeorológicos para a quantificação da temperatura e umidade relativa do ar (Cunha et al., 2001).

Bindon (1965) recomenda que os termopares do psicrômetro devam ser protegidos e submetidos a uma corrente forçada de ar para minimizar os efeitos ambientais sobre o coeficiente psicrométrico, e com isso, obter uma melhor exatidão nas medidas (ASHRAE STANDARD 41.6, 1994; Brionizio, 2006). Na prática fixa-se um micro-ventilador de forma a aspirar para fornecer um fluxo constante de ar e proporcionar evaporação da água contida na mecha de algodão do termopar de bulbo úmido, possibilitando, assim a coleta dos dados de temperatura de bulbo úmido de forma precisa e confiável. Esse fluxo de ar (aspiração) deve ser fornecido antes da leitura dos bulbos seco e úmido, para que o bulbo úmido esteja em equilíbrio no momento da medida.

A automação tem gerado enormes avanços na obtenção de dados, pois permite o acesso a medidas em tempo real, e, portanto, a tomada rápida de decisões, tais como: na estimativa da exigência de água e desenvolvimento das culturas, stress do gado, índices de secagem do feno, determinação do momento de pulverização para o controle de pragas e doenças em plantações (Silva e Moraes, 2002). Assim como na obtenção de dados, a aspiração em um psicrômetro de termopar pode ser facilitada pela automatização com o uso de um micrologger, pois a coleta e o registro de dados de forma automática possibilitam a coleta de grande quantidade de dados de temperatura de bulbos seco e úmido, facilitando a determinação da umidade relativa, assim como, à eliminação de erros humanos, de digitação, perda de dados, sincronismo da leitura entre vários instrumentos e frequência de leitura com intervalos precisos (Vilela et al., 2001; Figueredo Jr et al., 2006).

No Brasil, atualmente, já se dispõem de vários modelos de micrologger que podem ser usados para a coleta de dados, os modelos da Campbell Scientific Inc., os quais são robustos e versáteis, efetuando medidas com precisão e a partir delas estimar outras variáveis a partir de cálculos matemáticos, além de outros, sempre objetivando a pesquisa experimental em condições e casos variados.

A maior parte das pesquisas utilizando psicrômetro aspirado de termopar conectado em micrologger, não detalham sobre a forma do funcionamento do micro-ventilador, ou se é controlado por algum equipamento eletrônico, tais como, em Grodzki et al. (1999), Galvão e Fisch (2000), Marin et al. (2001), Silva (2001), Cordeiro (2003), Righi (2004), Guiselini et al. (2007), Silva et al. (2007), Pezzopane et al. (2007) e Scaranari 
et al. (2008), os quais não apresentam a programação e conexão em datalogger, dificultando a reprodução do procedimento.

Uma das maiores dificuldades dos que se utilizam dos psicrômetros aspirados de termopar, têm sido a sua programação e a conexão, pois neste caso, trata-se de um instrumento que exige cuidados na forma de programação, conexão e manuseio diário na obtenção de suas medidas de forma confiável, fazendo com que seja pouco utilizado em estudos agrometeorológicos e em áreas afins. Como atualmente, as pesquisas realizadas não detalham como o micro-ventilador é controlado, este trabalho teve o objetivo de fornecer a programação e conexão do psicrômetro aspirado de termopar tipo T conectado nos microloggers CR10X e CR23X da Campbell Scientific Inc., avaliando-se a qualidade das medidas obtidas de temperatura e umidade relativa do ar em relação a um sensor Vaisala HMP50 como referência.

\section{DADOS E METODOLOGIA}

\subsection{Psicrômetro aspirado}

O psicrômetro aspirado foi construído com tecnologia e material relativamente simples, utilizando-se dos seguintes componentes: tubos de PVC de 2" e 4" com $15 \mathrm{~cm}$ de comprimento, dois "caps" de 4" com perfuração de 2 " no centro, um micro-ventilador ("cooler" de computador) de 12 VDC de $6 \mathrm{~cm}$ de diâmetro e um reservatório para água destilada. Os termopares foram do tipo $\mathrm{T}$ (cobre-constantan) de bitola 2x24 AWG com junção exposta, que proporciona um tempo de resposta muito pequeno, entre 1-2 segundos, e com grande sensibilidade a pequenas alterações de temperatura (WMO, 2008). O mesmo foi inserido no centro do tubo de PVC de 2", de forma que o termopar úmido ficou próximo ao micro-ventilador, modelo conforme descrito por Marin et al. (2001) (Figura 1).

O tempo necessário para que o bulbo úmido atinja leitura estável depende da taxa de ventilação e da temperatura de bulbo úmido real, sendo que um termômetro de mercúrio em vidro com ventilação natural geralmente requer cerca de
15 minutos, e um termômetro aspirado exige um tempo muito mais curto (WMO, 2008). No momento da leitura o psicrômetro aspirado, o bulbo úmido deve estar em equilíbrio térmico com o ar circundante, sendo que, para termômetros de mercúrio em vidro, o tempo esperado para a estabilidade de leitura é de 2 a 3 minutos, e como o termopar apresenta um tempo de resposta bem menor e a mecha de algodão fica constantemente úmida, considerou-se 1 minuto tempo suficiente para a estabilidade da leitura no termopar.

A mecha de algodão colocada no termopar de bulbo úmido foi mantida constantemente úmida, e utilizou-se um micro-ventilador de forma que aspirasse o ar do tubo menor e criasse um fluxo constante de ar para proporcionar evaporação da água na mecha (capilaridade) para medidas corretas de temperatura de bulbo úmido no momento da leitura pelo micrologger, sendo substituída sempre que fosse necessário, ou seja, em função do seu estado e condição de umedecimento.

O micro-ventilador usado foi de 12 VDC nos microloggers da Campbell Scientific Inc., facilitando com isso, o uso de energia de acionamento do mesmo a partir da fonte de abastecimento 12 VDC do micrologger em condições de campo, as quais normalmente são completamente isoladas e distantes de rede elétrica ou de qualquer outra fonte.

De acordo com a primeira Lei Termoelétrica, a força eletromotriz $(\varepsilon)$ de um termopar depende apenas da natureza dos condutores e da diferença de temperatura entre as junções de contato. Assim, quando se mantém uma das junções do termopar a uma temperatura conhecida, é possível calcular a temperatura do ar através da expressão:

$$
\mathcal{E}=k\left(T_{a r}-T_{r e f}\right) \Rightarrow T_{a r}=\frac{\varepsilon+k\left(T_{r e f}\right)}{k}
$$

onde $\varepsilon$ é a tensão termoelétrica gerada pelo termopar $(\mathrm{mV})$; $k$ a constante termoelétrica que depende do tipo de material do termopar $\left(\mathrm{mV}^{\circ} \mathrm{C}^{-1}\right) ; T_{a r}$ a temperatura do ar que se deseja medir $\left({ }^{\circ} \mathrm{C}\right)$; e $T_{\text {ref }}$ a temperatura de referência que deve ser conhecida $\left({ }^{\circ} \mathrm{C}\right)$. Neste caso foi usado o termopar tipo $\mathrm{T}(k=$ $\left.0,041 \mathrm{mV}^{\circ} \mathrm{C}^{-1}\right)$.

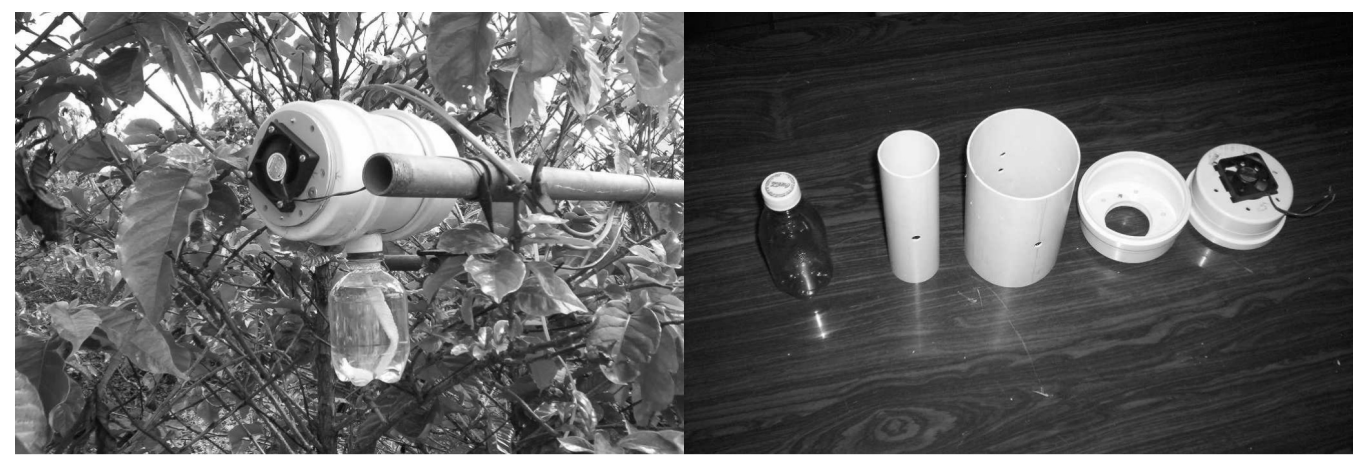

Figura 1 - Componentes usados na confecção de psicrômetro aspirado de termopares. 


\subsection{Programa - instruções do micrologger CR10 e/ou CR10X (CAMPBELL SCI, 1986-2001)}

\author{
1: Internal Temperature (P17) \\ 1:2 Loc [ T_Ref ] \\ 2: If time is (P92) \\ 1: 9 Minutes (Seconds --) into a \\ 2: 10 Interval (same units as above) \\ 3: 41 Set Port 1 High (Port 1-8) \\ 3: If time is (P92) \\ 1: $0 \quad$ Minutes (Seconds --) into a \\ 2: 10 Interval (same units as above) \\ 3: 30 Then Do \\ 4: Thermocouple Temp (DIFF) (P14) \\ 1:2 Reps \\ 2: $2 \quad 7.5 \mathrm{mV}$ Slow Range \\ 3: 1 DIFF Channel \\ 4: 1 Type T (Copper-Constantan) \\ 5:2 Ref Temp (Deg. C) Loc [ T_Ref ] \\ 6: 7 Loc [ Tempar_1 ] \\ 7: $1.0 \quad$ Mult \\ 8: 0.0 Offset \\ 5: Do (P86) \\ 1: $\underline{51}$ Set Port 1 Low (Port 1-8)
}

Obs: cada instrução contém os parâmetros, por exemplo, instrução P14 tem 8 parâmetros.

\subsection{Comentários das instruções - micrologger CR10 e/ou CR10X}

Instrução P17 - $\mathrm{n}^{\circ}$ 1: temperatura medida internamente no micrologger, usada como referência para o cálculo da medida do termopar (Equação 1).

Instrução P92 - $\mathrm{n}^{\circ}$ 2: permite que 1 minuto antes da leitura (9-10 min) dos termopares de bulbo seco e úmido, o micro-ventilador ligue e aspire o tubo de diâmetro menor onde se encontra a ponta dos termopares, aspirando por 1 minuto. Isto é feito a partir do parâmetro 3 , onde o $\underline{4}$ ativa a porta de controle 1 (41) que liga o micro-ventilador através da ponte entre a porta de controle $\underline{1}$ e o SW $12 \mathrm{~V}$ CTRL, ativando o SW $12 \mathrm{~V}$

Instrução P92 - $\mathrm{n}^{\circ}$ 3: define que sejam feitas medidas a cada 10 minutos dos termopares de bulbo seco e úmido antes do micro-ventilador ser desligado, sendo que 1 minuto antes da medida o micro-ventilador liga.

Instrução P14 - $\mathrm{n}^{\circ}$ 4: faz a leitura dos termopares de bulbo seco e úmido a cada 10 minutos em função da temperatura referência medida ( $T_{-}$Ref) no micrologger. O parâmetro 2 indica a faixa de medida do tipo de termopar $\left(7,5 \mathrm{mV}=-131\right.$ a $131{ }^{\circ} \mathrm{C}$, para uma temperatura de referência de $20^{\circ} \mathrm{C}$ ). Parâmetro 3: o número 1 sublinhado indica o canal a ser conectado o termopar de forma diferencial. Neste caso, com 2 repetições, conecta-se o primeiro termopar no par diferencial $\underline{1 \mathrm{HL}}$ e o segundo no par $\underline{2 \mathrm{HL}}$, sendo que o cobre (fio azul) inserido no $\mathrm{H}$ e o cosntantan (fio vermelho) no L. É possível também utilizar a instrução P13 que permite conexão SE, permitindo instalar o dobro de termopares. No caso SE, liga-se o primeiro par cobre-constantan no $\mathrm{H}$ e $\mathrm{G}$, e o segundo par no $\mathrm{L}$ e $\mathrm{G}$, do par $\underline{\mathrm{HL}}$, sendo que o cobre entra no $\mathrm{H}$ ou $\mathrm{L}$ e o constantan sempre no $\mathrm{G}$, como no esquema (Figura 2).

Parâmetro 4: indica o tipo de termopar (tipo $\mathrm{T} \Rightarrow \mathrm{k}=$ $\left.0,041 \mathrm{mV}^{\circ} \mathrm{C}^{-1}\right)$.

Existem diferentes tipos de termopares em função da combinação de diferentes materiais, tais como: ferro-constantan, cromel-alumel, cobre-constantan, platina/platina-ródio, cromelconstantan e niquel-cromel. A escolha dos materiais depende da faixa de trabalho, da precisão e da diferença de tensão gerada na faixa de trabalho, e da resistência dos materiais às condições de processo.

Instrução P86 - $\mathrm{n}^{\circ}$ 5: desativa (ㅁ) a porta 1 de controle (51), tendo como opções as portas de 1-8, que desliga o microventilador, depois que foi feita a medida dos termopares.

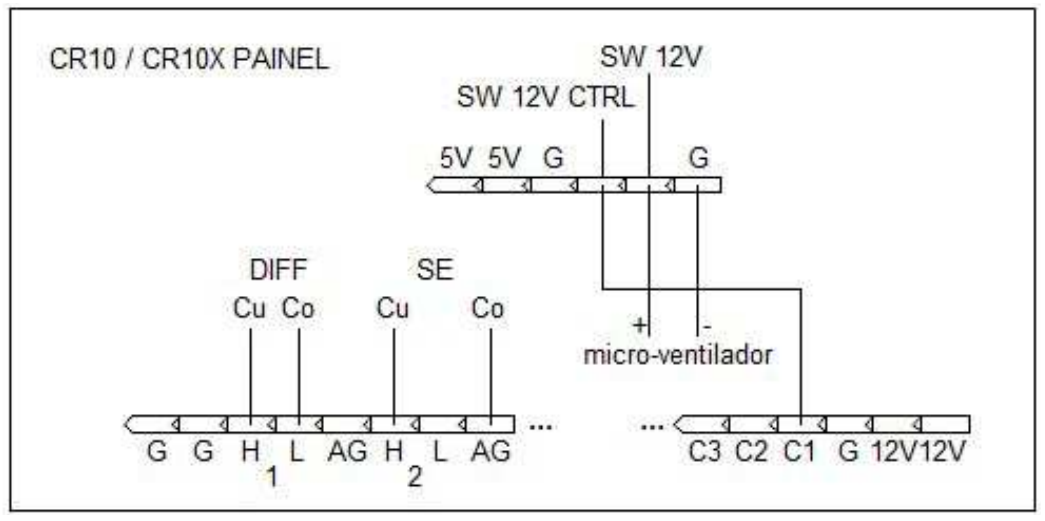

Figura 2 - Esquema de conexão dos termopares de bulbo seco e úmido do psicrômetro - CR10 e CR10X $(\mathrm{Cu}=\mathrm{cobre} ; \mathrm{Co}=\mathrm{constantan})$. 
As conexões deste procedimento no micrologger CR10 e/ou CR10X podem ser visualizadas no esquema da Figura 2.

\subsection{Programa - instruções do micrologger CR23X (CAMPBELL SCI, 1986-1988)}

\section{1: Panel Temperature (P17)}

$1: 2 \quad$ Loc [ T_Ref ]

2: If time is (P92)

1: $\underline{9}$ Minutes (Seconds --) into a

2: 10 Interval (same units as above)

3: $\underline{49}$ Turn On Switched 12V

3: If time is (P92)

1: $0 \quad$ Minutes (Seconds --) into a

2: 10 Interval (same units as above)

3: 30 Then Do

4: If Flag/Port (P91)

5: Thermocouple Temp (DIFF) (P14)

1:2 Reps

2: $21 \quad 10 \mathrm{mV}, 60 \mathrm{~Hz}$ Reject, Slow Range

3: $01 \quad$ DIFF Channel

4: 01 Type $\mathrm{T}$ (Copper-Constantan)

5:2 Ref Temp (Deg. C) Loc [ T_Ref ]

6: 3 Loc [ TempPAR_1 ]

7: $1.0 \quad$ Mult

8: $0.0 \quad$ Offset

6: Do (P86)

1: $\underline{59}$ Turn Off Switched $12 \mathrm{~V}$

1: $\underline{49}$ Do if Switched $12 \mathrm{~V}$ is On

2: $30 \quad$ Then Do

\subsection{Comentários das instruções - micrologger CR23X}

Instrução P17 $-\mathrm{n}^{\circ}$ 1: temperatura medida internamente no micrologger, usada como referência para o cálculo da medida do termopar (Equação 1).
Instrução P92 - no 2: permite que 1 minuto antes da leitura (9-10 $\mathrm{min}$ ) dos termopares de bulbo seco e úmido, o micro-ventilador ligue e aspire o tubo de diâmetro menor onde se encontra a ponta dos termopares, aspirando por 1 minuto. Isto é feito a partir do parâmetro 3 , onde o $\underline{49}$ ativa o microventilador.

Instrução P92 - $\mathrm{n}^{\circ}$ 3: define que as medidas sejam feitas a cada 10 minutos dos termopares de bulbo seco e úmido antes do micro-ventilador ser desligado, sendo que 1 minuto antes o micro-ventilador liga.

Instrução P91 - $\mathrm{n}^{\circ}$ 4: define condição para ativar o SW $12 \mathrm{~V}$ (interruptor), liga o micro-ventilador.

Instrução P14 - $\mathrm{n}^{\circ}$ 5: faz a leitura dos termopares de bulbo seco e úmido a cada 10 minutos em função da temperatura referência medida ( $\mathrm{T} \_$Ref) no micrologger. $\mathrm{O}$ parâmetro 2 indica a faixa de medida do tipo de termopar (10 $\mathrm{mV}=-131$ a $131{ }^{\circ} \mathrm{C}$, para uma temperatura de referência de 20 ${ }^{\circ} \mathrm{C}$ ). Parâmetro 3: o número 1 sublinhado indica o canal a ser conectado o termopar de forma diferencial. Neste caso, com 2 repetições, conecta-se o primeiro termopar no par diferencial $\underline{1 H L}$ e o segundo no par $2 \mathrm{HL}$, sendo que o cobre (fio azul) inserido no $\mathrm{H}$ e o constantan (fio vermelho) no L. É possível também utilizar a instrução $\mathrm{P} 13$, que permite conexão $\mathrm{SE}$, permitindo instalar o dobro de termopares. No caso SE, liga-se o primeiro par cobre-constantan no $\mathrm{H}$ e terra, e o segundo par no $\mathrm{L}$ e terra, do par $\underline{1 \mathrm{HL}}$, sendo que o cobre entra no $\mathrm{H}$ ou $\mathrm{L}$ e o cobre-constantan no terra (Figura 3 ).

Parâmetro 4: indica o tipo de termopar (tipo $\mathrm{T} \Rightarrow \mathrm{k}=$ $\left.0,041 \mathrm{mV}^{\circ} \mathrm{C}^{-1}\right)$.

Instrução P86 - $\mathrm{n}^{\circ}$ 6: desativa ( $\left.\underline{59}\right)$, que desliga o microventilador, depois que foi feita a medida dos termopares.

As conexões deste procedimento no micrologger CR23X podem ser visualizadas no esquema da Figura 3.

Com termopares de cobre-constantan de bulbos seco e úmido (psicrômetro) foi possível obter, através das relações psicrométricas, os valores de umidade relativa do ar:

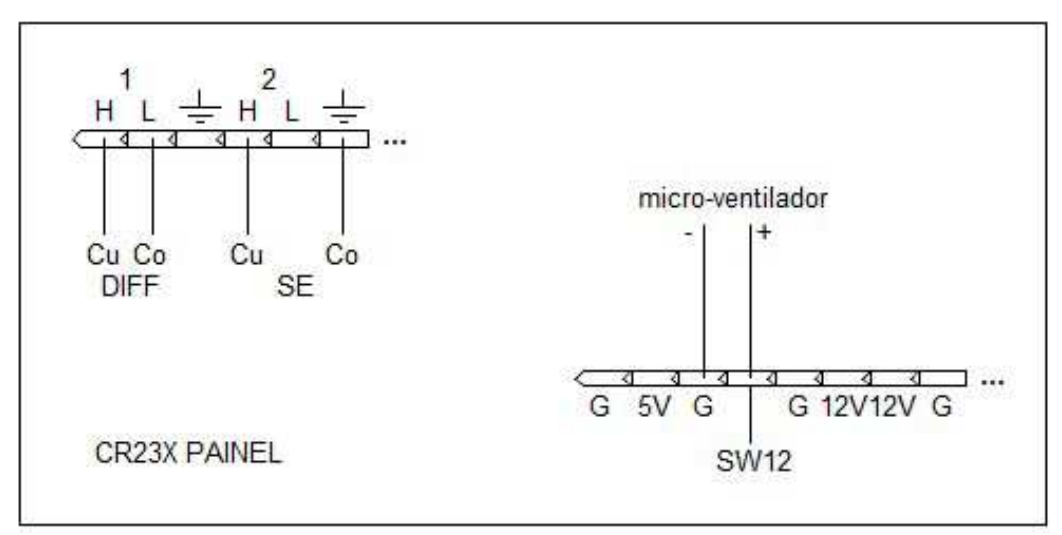

Figura 3 - Conexão dos termopares de bulbo seco e úmido do psicrômetro - $\mathrm{CR} 23 \mathrm{X}$. ( $\mathrm{Cu}=\mathrm{cobre} ; \mathrm{Co}=$ constantan). 


$$
\begin{aligned}
& U R=\frac{e_{a}}{e_{s}} 100 \\
& \text { onde } e_{a}=e_{s u}-A P\left(t_{s}-t_{u}\right) \\
& e_{s u}=0,611.10^{\left(\frac{7,5 . t_{u}}{237,3+t_{u}}\right)} \\
& e_{s}=0,611.10^{\left(\frac{7,5 \cdot t_{s}}{237,3+t_{s}}\right)}
\end{aligned}
$$

sendo que $U R$ é a umidade relativa do ar em $\% ; e_{a}$ a pressão parcial de vapor d'água em $\mathrm{kPa} ; e_{s}$ a pressão de saturação de vapor d'água à temperatura de bulbo seco em $\mathrm{kPa} ; e_{s u}$ a pressão de saturação de vapor d'água à temperatura de bulbo úmido em $\mathrm{kPa} ; A$ a constante psicrométrica para junção com ventilação forçada $\left(67.10^{-5}{ }^{\circ} \mathrm{C}^{-1}\right) ; P$ a pressão atmosférica do local $(94,36$ $\mathrm{kPa}) ; t_{s}$ a temperatura do termopar de bulbo seco em ${ }^{\circ} \mathrm{C}$; e $t_{u}$ a temperatura do termopar de bulbo úmido em ${ }^{\circ} \mathrm{C}$.

Para efeito comparativo, utilizaram-se sensores Vaisala modelo HMP50 como padrão de referência, pois sendo um higrômetro capacitivo não é considerado padrão para a calibração de instrumentos que medem a UR (Allen et al., 1994), mas mesmo assim foi utilizado para efeito comparativo em função de apresentar alta qualidade metrológica e ser usado na maioria das estações automáticas (WMO, 2008). O mesmo incorpora um termistor-resistivo na faixa de medida de temperatura entre $-40 \mathrm{a}+60{ }^{\circ} \mathrm{C}$, com erro variando entre $\pm 0,5 \mathrm{a}$ $\pm 1,5^{\circ} \mathrm{C}$, e um higrômetro capacitivo com acuracidade de $\pm 3 \%$ de 0 a $90 \%$ e de $\pm 5 \%$ na faixa de 90 a $98 \%$, e com erro variando entre $\pm 1,0$ a $\pm 1,5 \% /{ }^{\circ} \mathrm{C}$ (CAMPBELL SCI, 1995-2009). Cada sensor Vaisala foi conectado a um abrigo meteorológico para evitar que fatores como chuva, vento e raios solares danifiquem as medidas, e segundo normas padrões o higrômetro foi posicionado à uma temperatura a $2 \mathrm{~m}$ acima do terreno (WMO, 2008), sendo que os psicrômetros de termopar também foram instalados a $2 \mathrm{~m}$.

As medidas foram obtidas próximas à Estação Agroclimatológica pertencente à área de Agrometeorologia do Departamento deCiênciasExatas daFaculdade deCiênciasAgrárias e Veterinárias, UNESP, Campus de Jaboticabal, SP (latitude: $21^{\circ}$ 14' 05" S; longitude: 48 17' 09" W; e altitude: 615,01 m).

O período de estudo foi de 04/09/2006 a 11/01/2007 com medidas não contínuas, englobando dias com temperatura do ar alta e umidade relativa baixa, e dias com umidade relativa do ar alta e temperatura do ar baixa, num total de 28 dias. A varredura dos dados foi feita a cada minuto com armazenamento dos dados médios a cada 10 minutos, das temperaturas de bulbo seco e úmido dos psicrômetros aspirados de termopares de cobre-constantan, e da temperatura e umidade relativa do ar pelo sensor Vaisala. Esses equipamentos foram conectados em dois microloggers independentes, o CR10X e CR23X da Campbell
Scientific, sendo um psicrômetro aspirado de termopar e um sensor Vaisala para cada micrologger.

Para a comparação dos valores de temperatura e/ ou umidade relativa do ar, obtidos a cada 10 minutos pelos equipamentos, utilizou-se o teste $\mathrm{t}$ ao nível de $5 \%$ de probabilidade para a comparação das médias, e também se utilizou os indicadores estatísticos: análise de regressão coeficiente de determinação $\left(\mathrm{R}^{2}\right)$, índice de concordância $(\mathrm{d})$, erro máximo absoluto (ME), erro médio absoluto (MBE) e eficiência (EF), segundo Willmott et al. (1985):

$$
\begin{aligned}
& d=1-\left[\frac{\sum_{i=1}^{n}\left(O_{i}-E_{i}\right)^{2}}{\sum_{i=1}^{n}\left(\left|O_{i}-\bar{E}\right|+\left|E_{i}-\bar{E}\right|\right)^{2}}\right] \\
& M E=\max \left(\left|E_{i}-O_{i}\right|\right)_{i=1}^{n} \\
& M B E=\frac{1}{n} \sum_{i=1}^{n}\left(E_{i}-O_{i}\right) \\
& E F=\frac{\sum_{i=1}^{n}\left(O_{i}-\bar{O}\right)^{2}-\sum_{i=1}^{n}\left(O_{i}-E_{i}\right)^{2}}{\sum_{i=1}^{n}\left(O_{i}-\bar{O}\right)^{2}}
\end{aligned}
$$

em que $E_{i}$ é o valor da temperatura e/ou umidade relativa do ar obtido pelo psicrômetro aspirado de termopar, $O_{i}$ o valor da temperatura e/ou umidade relativa do ar obtido pelo sensor Vaisala, $\bar{E}$ a média da temperatura e/ou umidade relativa do ar obtida pelo psicrômetro aspirado de termopar, $\bar{O}$ a média da temperatura e/ou umidade relativa do ar obtida pelo sensor Vaisala, e $u$ o número de observações. Se $E_{i}$ é igual a $O_{i}$ tem-se que: $M E=M B E=0$ e $R^{2}=d=E F=1$.

\section{RESULTADOS E DISCUSSÃO}

A partir de uma amostra de 4.218 valores, medidos a cada 10 minutos, a temperatura do ar (T) medida pelo psicrômetro aspirado de termopar (Ps) apresentou-se sempre menor que a do sensor Vaisala HMP50 (Va). Já no caso da umidade relativa do ar (UR), derivada da temperatura do bulbo úmido obtida pelo sensor Ps apresentou os maiores valores, sendo que a UR obtida a partir do sensor Ps foi estatisticamente diferente da medida pelo sensor Va (Tabela 1), indicando que os sensores Va se encontravam semelhantes na calibração, sendo que o termômetro de resistência de platina é o mais exato e estável (Santos e Petkovic, 1993).

A média e o desvio-padrão (s) da T e UR permitem calcular o intervalo de confiança (IC), e por meio dele, obtém-se os limites mínimo e máximo que esses elementos meteorológicos atingem no período estudado (Pimentel Gomes, 1984) para cada tipo de sensor. Isto quer dizer, por exemplo, 
Tabela 1 - Valores médios de temperatura $\left(\mathrm{T},{ }^{\circ} \mathrm{C}\right)$ e umidade relativa do ar (UR, \%) obtidos pelos sensores Vaisala (Va) e psicrômetro de termopar (Ps) conectados em micrologger CR10X e CR23X. Jaboticabal, SP, 2006.

\begin{tabular}{|c|c|c|c|c|c|c|c|}
\hline \multirow{2}{*}{$\begin{array}{c}\text { Equipamento / } \\
\text { Sensor }\end{array}$} & \multirow{2}{*}{$\begin{array}{c}\text { Tamanho } \\
\mathrm{N}\end{array}$} & \multicolumn{3}{|c|}{$\mathrm{T}\left({ }^{\circ} \mathrm{C}\right)$} & \multicolumn{3}{|c|}{ UR (\%) } \\
\hline & & Média & IC & $\mathrm{s}$ & Média & IC & $\mathrm{s}$ \\
\hline$C R 10 X-V a$ & 4218 & $23,0 \mathrm{a}$ & $\pm 0,1$ & 5,2 & $68,3 \mathrm{~A}$ & $\pm 0,6$ & 20,3 \\
\hline$C R 23 X-V a$ & 4218 & $23,2 \mathrm{a}$ & $\pm 0,1$ & 5,2 & $67,6 \mathrm{~A}$ & $\pm 0,6$ & 20,6 \\
\hline$C R 10 X-P S$ & 4218 & $22,9 \mathrm{a}$ & $\pm 0,1$ & 5,2 & $74,3 \mathrm{~B}$ & $\pm 0,6$ & 20,3 \\
\hline$C R 23 X-P s$ & 4218 & $23,0 \mathrm{a}$ & $\pm 0,1$ & 5,3 & $75,0 \mathrm{~B}$ & $\pm 0,6$ & 20,2 \\
\hline
\end{tabular}

* Valores médios seguidos da mesma letra na coluna não diferem entre si ao nível de 5\% pelo teste t.

IC = intervalo de confiança; $\mathrm{s}=$ desvio padrão.

que $95 \%$ das $\mathrm{T}$ ocorridas no período estudado estavam entre 22,9 e $23,1^{\circ} \mathrm{C}$ para o sensor Va, enquanto que para o sensor Ps ficaram entre 22,8 e $23,0^{\circ} \mathrm{C}$, ambos conectados no micrologger CR10X (Tabela 1).

A qualidade de uma medida está associada à precisão e a exatidão. A precisão representa a dispersão das medidas em relação a um valor médio, associado ao erro padrão, e a exatidão assegura que a medida coincida com o valor real da grandeza considerada.

A partir do IC é possível avaliar as medidas de um sensor em relação ao outro, para a verificação daquele que apresenta o menor erro - o mais preciso, pois o IC mostra os limites de precisão de cada sensor. Importante frisar que a incerteza da medida da UR depende da incerteza da medida dos termopares do psicrômetro aspirado. Segundo a ASHRAE STANDARD 41.6 (1994), quando se deseja uma incerteza menor que $\pm 2 \%$ na UR, os termopares terão que indicar temperaturas com incerteza menor que $\pm 0,1^{\circ} \mathrm{C}$, e neste caso, ambos os sensores, Va e Ps, apresentaram incertezas dentro da faixa exigidas pelas normas para a $\mathrm{T}\left( \pm 0,1^{\circ} \mathrm{C}\right)$ e bem menores para a UR $( \pm 0,6 \%)$, indicando boa precisão dos sensores (Tabela 1).
Segundo Reyes Cac (2005) a incerteza da medida da UR é dependente do conteúdo de umidade no ar; no intervalo de umidade que vai de 20 a 50\% a incerteza é em torno de 4,0\%, e no intervalo de umidade que vai de 74 a $100 \%$ a incerteza é em torno de 2,0\%. Já segundo Bell (1996) as incertezas da UR devem variar de 2 a $5 \%$.

No entanto, a precisão não garante exatidão na medida, pois um sensor pode apresentar medidas ao longo do tempo com pouca ou nenhuma dispersão entre suas medidas, ou seja, preciso, mas, no entanto, com nenhuma exatidão, pois apresenta medidas da mesma grandeza muito distantes de um sensor padrão, indicando que precisa de calibração.

A exatidão está associada ao $\mathrm{MBE}$ do sensor Ps em relação ao sensor referência $(\mathrm{Va})$. O sensor Ps conectado ao CR10X foi o mais exato nas medidas de T e UR, em função dos menores valores de MBE, de 0,17 e 6,06, respectivamente (Tabela 2).

Ambos os sensores Ps, o conectado ao CR10X e o conectado ao CR23X, estão dentro dos limites permissíveis de erros para a medida de T, pois segundo Serralheiro (2011) e de acordo com a norma IEC 60584-2 (1989), os limites para

Tabela 2 - Indicadores estatísticos entre a temperatura $\left(\mathrm{T},{ }^{\circ} \mathrm{C}\right)$ e umidade relativa do ar (UR, \%) obtida por sensores psicrômetro aspirado (Ps) e Vaisala (Va) conectados nos microloggers CR10X e CR23X: coeficiente de determinação ( $\mathrm{R}^{2}$ ), índice de concordância (d), erro máximo (ME), erro médio absoluto (MBE) e eficiência (EF). Comparação feita entre os sensores (Ps x Va), independente do micrologger. Jaboticabal, SP, 2006.

\begin{tabular}{|c|c|c|c|c|c|c|c|}
\hline $\begin{array}{c}\text { Sensores Ps } \\
\text { x Va }\end{array}$ & $\mathrm{N}$ & $\overline{\mathrm{R}^{2}}$ & $\mathrm{~d}$ & $\mathrm{ME}$ & $\overline{\mathrm{MBE}}$ & $\overline{\mathrm{EF}}$ & $\mathrm{Tps}=\mathrm{b}(\mathrm{Tva})$ \\
\hline$T\left({ }^{\circ} \mathrm{C}\right)$ & & & & $\left({ }^{\circ} \mathrm{C}\right)$ & $\left({ }^{\circ} \mathrm{C}\right)$ & & $\left({ }^{\circ} \mathrm{C}\right)$ \\
\hline CR10X & 4218 & 0,9877 & 0,9998 & 2,65 & 0,17 & 0,9994 & Tps $=0,9929$ (Tva) \\
\hline CR23X & 4218 & 0,9893 & 0,9998 & 3,00 & 0,28 & 0,9993 & Tps $=0,9888(\mathrm{Tva})$ \\
\hline UR (\%) & & & & $(\%)$ & $(\%)$ & & $(\%)$ \\
\hline CR10X & $\begin{array}{l}4218 \\
\end{array}$ & 0,9886 & 0,9962 & 18,76 & 6,06 & 0,9802 & URps $=1,0810$ (URva) \\
\hline CR23X & 4218 & 0,9911 & 0,9947 & 15,04 & 7,48 & 0,9721 & URps $=1,0995$ (URva) \\
\hline
\end{tabular}


termopares do tipo T são de $\pm 1{ }^{\circ} \mathrm{C}$ ou $\pm 0,75 \%$. Mesmo para a obtenção da UR, segundo Bell (1996), a cada $\pm 1^{\circ} \mathrm{C}$ de mudança na $T$, a UR pode variar em até $\pm 6,3 \%$, sendo que o psicrômetro apresenta erros na faixa de $\pm 2 \mathrm{a} \pm 5 \%$ para a UR.

Houve boa concordância nos valores obtidos entre os dois tipos de sensores, Ps e Va (Tabela 2) e também entre os dois tipos de microloggers, CR10X e CR23X (Tabela 3), tanto para T como para UR, em função da alta correlação confirmada pelos indicadores estatísticos e pela análise de regressão (Tabelas 2 e 3; Figuras 4 e 5).

Pela Tabela 2 observa-se que a maior parte dos valores de $\mathrm{T}$ medidos pelo sensor Ps foram superestimados em relação aos medidos pelo sensor Va (Figura 4). Para a UR, ocorreu o contrário, a maior parte dos valores medidos pelo sensor Ps foi subestimada em relação aos medidos pelo sensor Va (Figura 5). O sensor Ps conectado ao CR10X apresentou os menores erros, ME e MBE, para as medidas de T e UR, sendo que com relação ao coeficiente $R^{2}, d$ e $E F$, apresentaram-se semelhantes apenas para a medida da T, enquanto que para a medida de UR, o sensor Ps conectado ao CR10X foi o que apresentou melhor estimativa (Tabela 2).

Utilizando-se o micrologger CR10X como coletor de 4.218 valores de $\mathrm{T}$ de bulbos seco e úmido de um psicrômetro de termopares, e controlando um micro-ventilador de 12 VDC para a estabilidade da medida da $\mathrm{T}$ de bulbo úmido, observou-se que a $\mathrm{T}$ foi subestimada na maior parte dos seus valores em aproximadamente $0,7 \%$, enquanto que a UR foi superestimada em 8,1\% (Tabela 2). Quando foi utilizado o micrologger CR23X, observou-se que a $\mathrm{T}$ foi subestimada na maior parte dos seus valores em $1,1 \%$, e a UR foi superestimada em 9,9\%, principalmente nos menores valores (Tabela 2 e Figura 4). A T foi a medida que apresentou valores de $d$ e $E F$ mais próximos de 1 , e os menores valores de $M E$ e $M B E$. Segundo Cunha e Martins (2004) além da alta concordância $\left(\mathrm{R}^{2}\right.$ e d $\left.>0,90\right)$, numa análise comparativa entre sensores, é importante também que haja um baixo erro absoluto médio e um baixo erro máximo ( $M B E$ e $M E$ próximos de zero) para garantir que ambos os sensores sejam semelhantes entre si nas medidas obtidas.

Tabela 3 - Indicadores estatísticos entre a temperatura $\left(\mathrm{T},{ }^{\circ} \mathrm{C}\right)$ e umidade relativa do ar (UR, \%) obtida por sensores psicrômetro aspirado (Ps) e Vaisala (Va) conectados nos microloggers CR10X e CR23X: coeficiente de determinação ( $\mathrm{R}^{2}$ ), índice de concordância (d), erro máximo (ME), erro médio absoluto (MBE) e eficiência (EF). Comparação feita entre os microloggers (CR23 x CR10), independente dos sensores. Jaboticabal, SP, 2006.

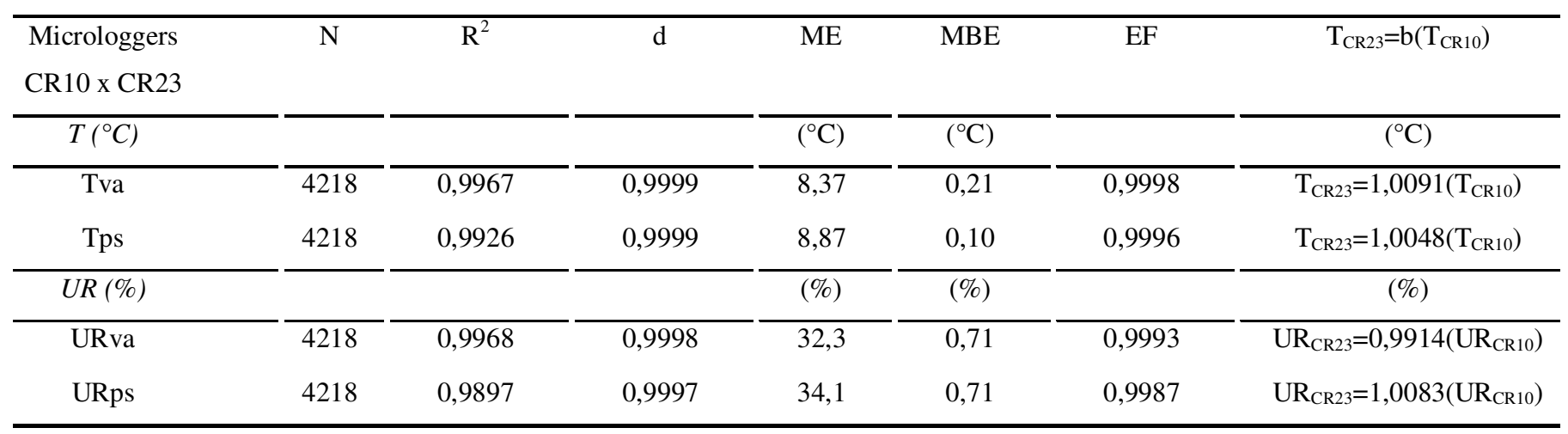
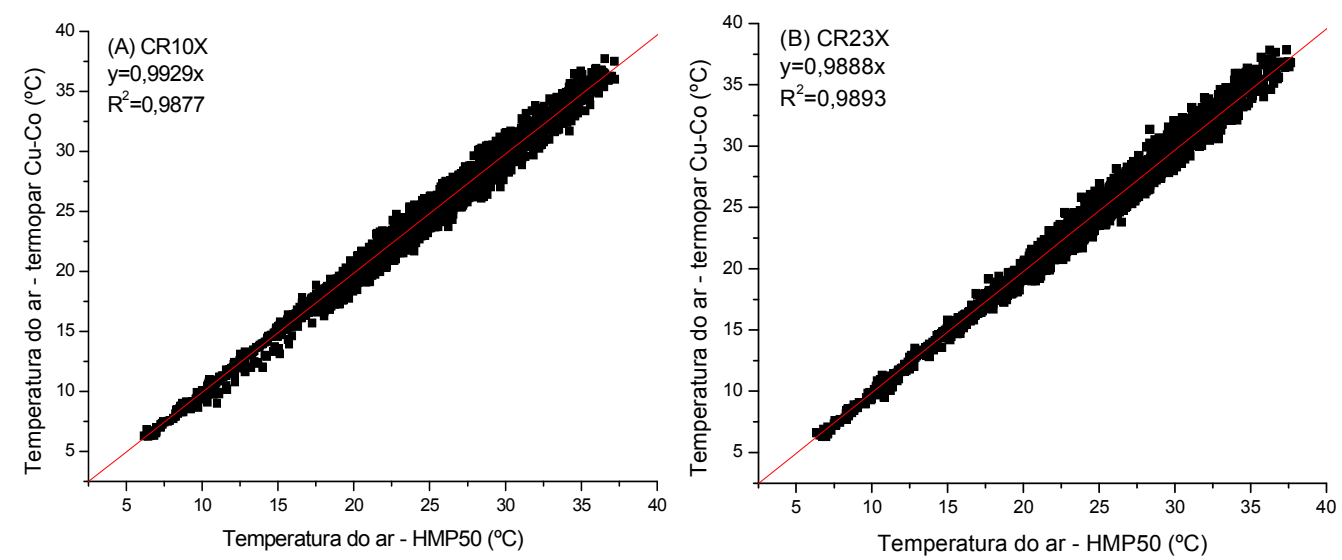

Figura 4 - Correlação entre os valores de temperatura do ar obtidos a partir do sensor HMP50 e um psicrômetro aspirado de termopar, para o CR10X (A) e para o CR23X (B). Jaboticabal, SP, 2006. 

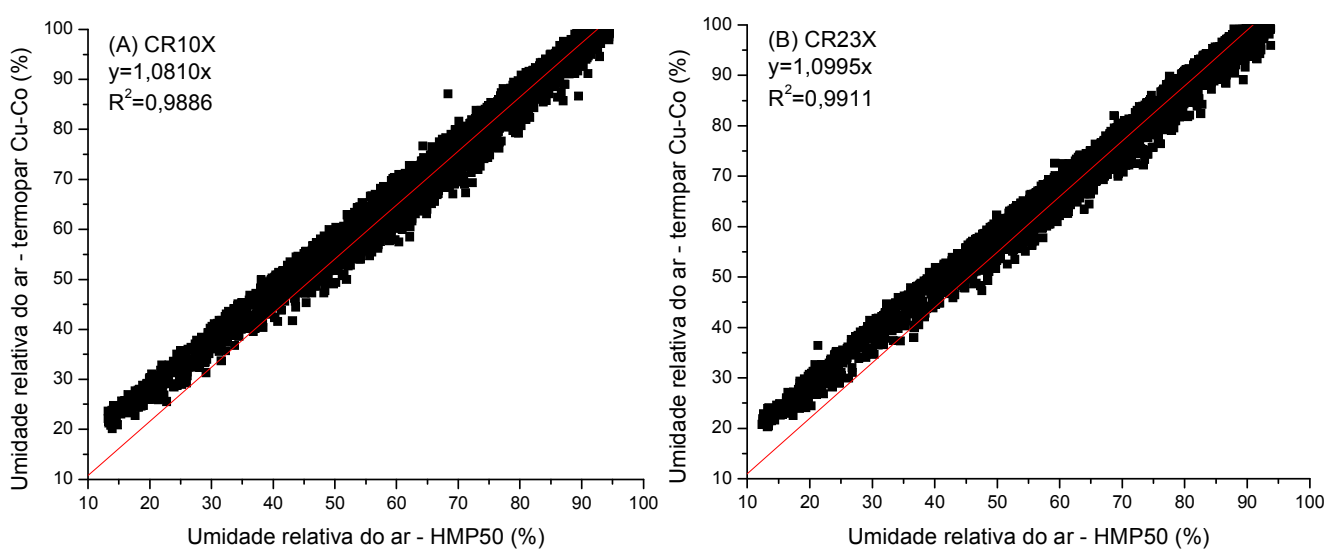

Figura 5 - Correlação entre os valores de umidade relativa do ar obtidos a partir do sensor HMP50 e um psicrômetro aspirado de termopar, para o CR10X (A) e para o CR23X (B). Jaboticabal, SP, 2006.

Marin et al. (2001) encontraram uma subestimativa de $1 \%$ na temperatura do ar e uma superestimativa de $5 \%$ na pressão atual de vapor (ea) por parte do psicrômetro aspirado em relação a um sensor comercial Vaisala modelo HMP45C. Isto significa dizer que a UR na pesquisa de Marin et al. (2001) foi superestimada em cerca de $6,5 \%$, enquanto que neste trabalho, quando se comparou a eaVa pelo eaPs, conectado ao CR10X, a superestimativa foi de $6,4 \%$, e de $8,1 \%$ a relação quando conectado ao CR23X, mostrando um valor pouco superior ao encontrado por Marin et al. (2001).

Tanto Marin et al. (2001) que analisaram apenas 4 dias, como Silva et al. (2011) que analisaram apenas 3 dias, tiveram os resultados comprometidos, pois este tipo de sensor é grandemente influenciado por UR baixas, o que causa piora na sua precisão e exatidão. Silva et al. (2011) encontraram uma superestimativa de $2,7 \%$ na UR obtida por psicrômetro de termopar em relação a um sensor Vaisala modelo HMP45D, numa faixa de 55 a $100 \%$. A utilização de curto período de tempo nas medidas pelos autores inviabiliza uma comparação adequada, e a faixa analisada, em que o psicrômetro apresenta medidas mais precisas, acaba mascarando a resposta do psicrômetro, não garantindo uma precisão e exatidão adequada, o que é devido ao curto período de análise e a faixa de medida da UR.

Neste trabalho, a faixa de medidas da UR variou entre 12,4 e $100 \%$ (Figura 5), aumentando os erros, e com isso, também a superestimativa da UR, evidenciando uma preocupação com relação ao uso desse tipo de sensor em pesquisas. Isso acontece porque quando em valores mais baixos da UR (menor que 50\%), a demanda atmosférica aumenta muito, e a evaporação da água da mecha de algodão que envolve o bulbo úmido do psicrômetro não consegue acompanhar com a mesma rapidez essa demanda devido à deficiência na capilaridade. Portanto, ao se utilizar este tipo de psicrômetro aspirado é importante estar atento ao sistema de umedecimento da mecha de algodão do bulbo úmido, o qual deve ser contínuo, pois se não houver capilaridade na mecha para mantê-lo sempre úmido, medidas erradas de bulbo úmido serão obtidas, e consequentemente de UR. Além disso, esse fenômeno físico pode ser afetado tanto pela baixa eficiência do micro-ventilador como pelo pó acumulado na mecha de algodão, o que acaba impermeabilizando a mecha e diminuindo a sua capilaridade nos momentos da medida, pois segundo ASHRAE STANDARD 41.6 (1994) a corrente de ar deve ser constante até que uma temperatura constante seja atingida no bulbo úmido.

Camerini et al. (2011) ao se utilizarem de um psicrômetro comercial, observaram que houve subestimativa de $2,6 \%$ para a T e uma superestimativa de $8,5 \%$ para a UR em relação a um sensor de T e UR da marca HOBO. Mesmo com altos percentuais de estimativa para a T e UR, os autores recomendam o uso do equipamento em estudos agrometeorológicos, mas, no entanto, em função desses resultados e por ter sido comparado com um sensor não padrão no meio científico (HOBO), o psicrômetro usado por Camerini et al. (2011) só deve ser utilizado em monitoramentos de ordem prática, sem critério científico.

Os sensores capacitivos, assim como o Vaisala (sensor referência), são caros e possuem melhor linearidade em valores mais baixos de UR, apresentando elevada incerteza e com histerese na resposta em umidade relativa acima de 90\%, o que exige alterações na calibração quando utilizados nestas condições (Bell, 1996). Esses sensores higrômetros tendem a perder a precisão com o tempo, e por isso, necessitam de verificações periódicas de suas calibrações.

Os sensores Va conectados em ambos os microloggers, CR10X e CR23X, apresentaram medidas de T e UR muito semelhantes, e sendo que os mesmos estavam adequadamente calibrados para essas medidas, os sensores Ps mediram a T com precisão e exatidão, mas no caso da UR apenas com precisão. Com isso, os psicrômetros de termopares são uma opção mais 
barata e com boa exatidão, mas, no entanto, a UR apresenta uma relativa dificuldade de ser medida na prática e a exatidão atingível não é tão boa (Dias, 2001).

O psicrômetro mede a quantidade de vapor d'água contido em uma amostra de ar próxima aos bulbos seco e úmido, sendo identificada a partir da evaporação da água da mecha do bulbo úmido. Quando as temperaturas são iguais nos bulbos seco e úmido, a UR é igual a $100 \%$, mas quando o ar não está saturado, ocorre o que se chama de equilíbrio dinâmico. A água para evaporar precisa de calor latente, então todo o calor cedido pelo ar será utilizado para evaporar a água da mecha de algodão, demonstrando a capacidade do ar em ceder calor para evaporar a água da mecha, e com isso, ocorre o resfriamento do bulbo úmido. Assim, quanto maior a capacidade do ar em remover o calor, menor será a umidade do ar, e maior será a evaporação da água contida na mecha do bulbo úmido.

Erros de superestimativa que ocorrem na medida da UR são devido ao bulbo úmido, ou seja, ventilação insuficiente na condução de calor para o bulbo úmido advinda da atmosfera, e a contaminação da mecha de algodão tornando-a impermeável e dificultando a sua capilaridade. Isto que acaba reduzindo a depressão psicrométrica, e levam a determinação de UR mais elevadas que os valores reais. Neste estudo, provavelmente houve uma elevação na temperatura da água do reservatório (Figura 1), pois o mesmo era desprotegido do efeito radiativo, o que pode ter levado a uma diminuição do resfriamento do bulbo úmido, e consequentemente, a um aumento da UR.

Normalmente, este tipo de psicrômetro apresenta boa estabilidade nas medidas, mas exige habilidade na manutenção, pois está propenso a erros na medida do bulbo úmido, quando a amostra de ar não é umedecida o suficiente pela evaporação da água contida na mecha (Bell, 1996). Apesar do psicrômetro aspirado de termopar ser simples, contém um micro-ventilador 12 VDC para aspirar a mecha de algodão contida no bulbo úmido, e tem como inconveniente, a necessidade de constante monitoramento do nível d'água do reservatório e das condições de limpeza e capilaridade da mecha de algodão, dificultando a total automatização do sistema. Outro problema é o formato do equipamento definido para uma melhor eficiência da aspiração do bulbo úmido, que desfavorece medidas precisas e acuradas, quando a ventilação fica deficiente, sendo muitas vezes a causa da superestimativa nas medidas de UR.

O efeito Seebeck do princípio termopar e as relações psicrométricas exigem conhecimento pelo usuário para evitar erros nas medições de temperatura e umidade do ar, e, portanto, para a obtenção de medidas reais e precisas a partir do método psicrométrico (termopares). É importante que os dois termopares em condições iguais (em bulbo seco) indiquem a mesma temperatura, e quando na forma de psicrômetro devem estar próximos o suficiente para medir o fluxo da mesma amostra de ar, desde que a medida de bulbo seco não seja influenciada pela evaporação da umidade da mecha do bulbo úmido (ASHRAE STANDARD 41.1, 1974). Além disso, a distância entre o reservatório e o termômetro deve ser de pelo menos 2 $\mathrm{cm}$ visando aumentar o alargamento do bulbo úmido (WMO, 2008). A mecha que envolve o bulbo úmido deve ser de algodão e estar bem justa ao termopar para evitar erros de medida, além de impurezas que acabam sendo depositadas na mecha ao longo do tempo, necessitando de limpeza ou troca (ASHRAE STANDARD 41.1, 1974). Os bulbos seco e úmido devem ser protegidos da chuva e da radiação solar por material isolante termicamente, e deve-se estar atento ao tempo necessário para que o bulbo úmido atinja uma leitura estável em função da taxa de ventilação (ISO, 2007), sendo que os termopares requerem baixas velocidades do ar, pois apresentam diâmetro pequeno e rápida resposta de medida.

\section{CONCLUSÕES}

As medidas de temperatura do ar apresentaram-se semelhantes entre os sensores usados, mas para as medidas de umidade relativa do ar, houve diferenças significativas entre os sensores Vaisala e o psicrômetro aspirado de termopar cobreconstantan.

Os indicadores estatísticos mostraram que a temperatura e umidade relativa do ar, medidas a partir do psicrômetro aspirado de termopar conectado ao CR10X, foi a mais precisa.

A correlação linear indicou que a temperatura do ar foi subestimada e a umidade relativa superestimada pelo psicrômetro aspirado de termopar cobre-constantan.

A partir de psicrômetro de termopar de cobre-constantan aspirado com micro-ventilador $12 \mathrm{VDC}$, com a programação e a conexão nos microloggers apresentados, é possível obter medidas de temperatura do ar com boa precisão e exatidão, mas, no entanto, com boa precisão e exatidão nem sempre atingida nas medidas de umidade relativa do ar, devido às dificuldades inerentes ao processo físico que ocorre no bulbo úmido relativas à habilidade, manutenção e a proteção adequada do reservatório devido aos efeitos radiativos.

A descrição da programação e da conexão do psicrômetro aspirado de termopar via 12 VDC para os microloggers CR10X e CR23X apresentada neste trabalho, facilita e permite aos usuários uma opção mais adequada em condição de campo, para efetuar estudos agrometeorológicas com baixo custo e bom desempenho.

A partir da comparação da medida de temperatura e umidade relativa do ar em relação ao sensor padrão através dos indicadores estatísticos usados, é possível identificar desvios e erros de leitura, podendo-se com isso indicar correções e assegurar precisão e exatidão nessas medidas. 


\section{REFERÊNCIAS BIBLIOGRÁFICAS}

ALLEN, S.J; BRENNER, A.J.; GRACE, J. A lowcost psychrometer form field measurements of atmospheric humidity. Plant, Cell and Environment, v.17, p.219-225, 1994.

ASHRAE STANDARD 41.1 - 1974. Standard measurement guide: section on temperature measurements, ASHRAE, Atlanta. Disponível em <http://www.ashrae.org/ publications/>. Acesso em 01 out. 2011.

ASHRAE STANDARD 41.6-1994. Methods for measurement of moist air properties, ASHRAE, Atlanta. Disponível em $<$ http://www.ashrae.org/publications/>. Acesso em 01 out. 2011.

BELL, S.A. A guide to the measurement of humidity (NPL Guide 103). Teddington: National Physical Laboratory. 1996.

BINDON, H.H. A critical review of tables and charts use in psychrometry. In: WEXLER, A. Humidity and moisture. New York: Reinhold, 1965, v.1, p.3-15.

BRIONIZIO, J.D. Estudo das metodologias de avaliação de temperatura e umidade em câmaras. 2006. 152f. Dissertação (Mestrado em Sistemas de Gestão) - Universidade Federal Fluminense, Niterói, 2006.

CAMERINI, N.L.; MENDES, L.B.; MOTA, J.K.M.; NASCIMENTO, J.W.B.; FURTADO, D.A. Avaliacão de instrumentos agrometeorológicos alternativos para o monitoramento da ambiência em galpões avícolas. Engenharia na Agricultura, v.19, p.125-131, 2011.

CAMPBELL SCI. CR10X Micrologger: operator's manual. Revision: 9/01. Logan, Utah: Copyright(C), 1986-2001.

CAMPBELL SCI. CR23X Micrologger: operator's manual. Revision: 10/98. Logan, Utah: CopyrightC, 1986-1998.

CAMPBELL SCI. HMP50: temperature and relative humidity probe. Revision: 10/09. Logan, Utah: Copyright $\subset$, 1995-2009.

CORDEIRO, M.B. Avaliação de sistemas de camas sobrepostas quanto ao conforto térmico e ambiental e ao desempenho zootécnico para suínos nas fases de crescimento e terminação. 2003. 63f. Dissertação (Mestrado em Engenharia Agrícola) - Universidade Federal de Viçosa, Viçosa, 2003.

CUNHA, A.R.; ESCOBEDO, J.F.; GALVANI, E. Avaliação de um psicrômetro de termopar de baixo custo. Revista Brasileira de Agrometeorologia, v.9, p.17-22, 2001.

CUNHA, A.R.; MARTINS, D. Estudo comparativo entre elementos meteorológicos obtidos em estações meteorológicas convencional e automática em Botucatu, SP, Brasil. Revista Brasileira de Agrometeorologia, v.12, p.103-111, 2004.
DIAS, J.B. Construção e validação de uma bancada para calibração de sensores para determinação da umidade relativa do ar. 2001. 137f. Dissertação (Mestrado em Engenharia Mecânica) - Universidade Federal do Rio Grande do Sul, Porto Alegre, 2001.

FIGUEREDO JR, L.G.M.; SILVA DIAS, N.; DUENHAS, L.H.; BOTREL, T.A. Construção e calibração de um manômetro de leituras digitais microprocessado. Irriga, v.11, p.492499, 2006.

FRITSCHEN, L.J.; GAY, L.W. Environmental instrumentation. New York: Springer-Verlag, 1979. 212p.

GALVÃO, J.A.C; FISCH, G. Balanço de radiação em área de pastagem na Amazônia. Revista Brasileira de Agrometeorologia, v.8, p.1-10, 2000.

GRODZKI, L.; DIAS, N.L.C.; CARAMORI, P. Psicrômetro ventilado para medidas micrometeorológicas de campo. In: CONGRESSO BRASILEIRO DE AGROMETEOROLOGIA, 11., 1999, Florianópolis. CDROM... Florianópolis: Epagri, 1999.

GUISELINI, C.; SENTELHAS, P.C.; PANDORFI, H.; HOLCMAN, E. Temperatura e umidade do ar em ambientes protegidos cobertos com plástico transparente associado à malha termo-refletora, instalada externa e internamente. Revista Brasileira de Agrometeorologia, v.15, p.29-38, 2007.

IEC 60584-2 - International Electrotechnical Commission. Thermocouples Part 2: Tolerances. Revision/ Edition: V. 1.1989.

ISO - Internacional Organization for Standardization. Norma n.17714. Meteorology - air temperature measurements: test methods for comparing the performance of thermometer shields/screens and defining important characteristics, Geneva, 2007.

MARIN, F.R.; ANGELOCCI, L.R.; COELHO FILHO, M.A.; VILLA NOVA, N.A. Construção e avaliação de psicrômetro aspirado de termopar. Scientia Agricola, v. 58, p.839-844, 2001.

PEZZOPANE, J.R.M.; PEDRO JR.; M.J., GALLO, P.B. Balanço de energia em cultivo de café a pleno sol e consorciado com banana 'Prata Anã'. Revista Brasileira de Agrometeorologia, v.15, p.169-177, 2007.

PIMENTEL GOMES, F. A estatística moderna na pesquisa agropecuária. Piracicaba: POTAFOS, 1984. 160p.

REYES CAC, F.E. Análise metrológica do comportamento transiente de um psicrômetro do tipo bulbo úmido e bulbo seco. 2005. 92f. Dissertação (Mestrado em Metrologia para Qualidade e Inovação) - Pontifícia Universidade Católica do Rio de Janeiro, Rio de Janeiro, 2005.

RIGHI, E.Z. Balanço de energia evapotranspiração de cafezal adensado em crescimento sob irrigação localizada. 2004. 151f. Tese (Dourado em Física do Ambiente 
Agrícola) - Escola Superior de Agricultura Luiz de Queiroz, Universidade de São Paulo, Piracicaba, 2004.

SANTOS, P.R.F.; PETKOVIC, S.G. Curso de termometria de contato. Duque de Caxias, RJ, 2003.

SCARANARI, C.; LEAL, P.A.M.; PELLEGRINO, G.Q. Estudo de simulações de microclimas em casas de vegetação visando à aclimatação de mudas micropropagadas de bananeira cv. Grande Naine. Revista Brasileira de Fruticultura, v.30, p.1001-1008, 2008.

SERRALHEIRO, W. Aquisição de dados. Instituto Federal de Santa Catarina, Campus de Araranguá. 2a Edição 2011. (material didático). Disponível em $<$ http://wiki.ifsc.edu.br/ mediawiki/images/e/e3/Aru_automacao_daq.pdf $>$. Acesso em 01 outubro 2011.

SILVA, C.R.; RAABE, J.; SILVA DIAS, N.; SILVA, T.J.A.; SANTOS, R.A. Desempenho de diferentes bitolas de termopar em um psicrômetro aspirado de baixo custo. Revista Caatinga, v.24, p.99-103, 2011.

SILVA, K.O.; MORAES, S.O. Desenvolvimento de um sistema automatizado de baixo custo para aquisição de dados de temperatura do ar. Revista Brasileira de Agrometeorologia, v.10, p.189-195, 2002.

SILVA, L.B. Análise da relação entre produtividade e conforto térmico: o caso dos digitadores do centro de processamento de dados e cobrança da Caixa Econômica Federal do Estado de Pernambuco. 2001. 84f. Tese (Doutorado em Engenharia de Produção) Universidade Federal de Santa Catarina, Florianópolis, 2001.
SILVA, T.J.A.; FOLEGATTI, M.V.; SILVA, C.R.; ALVES JR.; J. BONFIM-SILVA, E.M. Balanço de energia e estimativa da evapotranspiração em culturas irrigadas de maracujazeiro pelo método da razão de Bowen. Engenharia Agrícola, v.27, p.392-403, 2007.

VILELA, L. A. A.; GERVÁSIO, E.S; SOCCOL, O.J.; BOTREL, T.A. Sistema para aquisição de dados de pressão e vazão usando o microcomputador. Revista Brasileira de Agrocomputação, v.1, p.25-30, 2001.

WHITE, G.M.; ROSS, I.R. Humidity. In: HENRY, Z.A.; ZOERB, G.A.; BIRTH, G.S. Instrumentation and measurement for environmental sciences. Saint Joseph: ASAE, 1991. p.8.01-8.13.

WMO - World Meteorological Organization. Guide to meteorological instruments and methods of observation, seventh edition, 2008. WMO n.8. Disponível em $<\mathrm{http}$ :/ www.wmo.int/pages/prog/www/IMOP/publications/ CIMO_Guide/CIMO\%20Guide\%207th\%20Edition,\%20 2008/CIMO_Guide-7th_Edition-2008.pdf $>$. Acesso em 01 out. 2011.

WILLMOTT, C. J.; ACKLESON, S. G.; DAVIS, R. E.; FEDDEMA, J. J.; KLINK, K. M.; LEGATES, D. R.; O'DONNELL, J.; ROWE, C. M. Statistics for the evaluation and comparison of models. Journal of Geophysical Research, v. 90, p. 8995-9005, 1985. 